\section{Impact of cytogenetic abnormalities on outcomes of adult Philadelphia-negative acute lymphoblastic leukemia after allogeneic hematopoietic stem cell transplantation: a study by the Acute Leukemia Working Committee of the Center for International Blood and Marrow Transplant Research}

Aleksandr Lazaryan, ${ }^{1}$ Michelle Dolan ${ }^{2}$ Mei-Jie Zhang ${ }^{3,4}$ Hai-Lin Wang ${ }^{3}$ Mohamed A. Kharfan-Dabaja, ${ }^{5}$ David I. Marks, ${ }^{6}$ Nelli Bejanyan, ${ }^{7}$ Edward Copelan, ${ }^{8}$ Navneet S. Majhail, ${ }^{9}$ Edmund K. Waller, ${ }^{10}$ Nelson Chao, ${ }^{11}$ Tim Prestidge, ${ }^{12}$ Taiga Nishihori, ${ }^{13}$ Partow Kebriaei, ${ }^{14}$ Yoshihiro Inamoto, ${ }^{15}$ Betty Hamilton, ${ }^{16}$ Shahrukh K. Hashmi, ${ }^{17,18}$ Rammurti T. Kamble, ${ }^{19}$ Ulrike Bacher, ${ }^{20}$ Gerhard C. Hildebrandt, ${ }^{21}$ Patrick J. Stiff, ${ }^{22}$ Joseph McGuirk, ${ }^{23}$ Ibrahim Aldoss, ${ }^{24}$ Amer M. Beitinjaneh, ${ }^{25}$ Lori Muffly, ${ }^{26}$ Ravi Vij, ${ }^{27}$ Richard F. Olsson ${ }^{28,29}$, Michael Byrne, ${ }^{30}$ Kirk R. Schultz, ${ }^{31}$ Mahmoud Aljurf, ${ }^{18}$ Matthew Seftel, ${ }^{32}$ Mary Lynn Savoie, ${ }^{33}$ Bipin N. Savani, ${ }^{34}$ Leo F. Verdonck, ${ }^{35}$ Mitchell S. Cairo, ${ }^{36}$ Nasheed Hossain, ${ }^{37}$ Vijaya Raj Bhatt, ${ }^{38}$ Haydar A. Frangoul, ${ }^{39}$ Hisham Abdel-Azim, ${ }^{40}$ Monzr Al Malki, ${ }^{24}$ Reinhold Munker, ${ }^{41}$ David Rizzieri, ${ }^{42}$ Nandita Khera, ${ }^{43}$ Ryotaro Nakamura, ${ }^{44}$ Olle Ringdén, ${ }^{45}$ Marjolein van der Poel, ${ }^{46}$ Hemant S. Murthy, ${ }^{47}$ Hongtao Liu, ${ }^{48}$ Shahram Mori, ${ }^{49}$ Satiro De Oliveira, ${ }^{50}$ Javier BolañosMeade, ${ }^{51}$ Mahmoud Elsawy, ${ }^{52}$ Pere Barba, ${ }^{53}$ Sunita Nathan, ${ }^{54}$ Biju George ${ }^{55}$ Attaphol Pawarode, ${ }^{56}$ Michael Grunwald, ${ }^{57}$ Vaibhav Agrawal, ${ }^{58}$ Youjin Wang, ${ }^{59}$ Amer Assal, ${ }^{60}$ Paul Castillo Caro, ${ }^{61}$ Yachiyo Kuwatsuka, ${ }^{62}$ Sachiko Seo, ${ }^{63}$ Celalettin Ustun, ${ }^{64}$ loannis Politikos, ${ }^{65}$ Hillard M. Lazarus, ${ }^{66}$ Wael Saber, ${ }^{3}$ Brenda M. Sandmaier, ${ }^{67}$ Marcos De Lima, ${ }^{68}$ Mark Litzow, ${ }^{69}$ Veronika Bachanova ${ }^{70}$ and Daniel Weisdorf, ${ }^{71}$ Acute Leukemia Committee of the CIBMTR $^{3}$

${ }^{1} \mathrm{H}$. Lee Moffitt Cancer Center and Research Institute, Tampa, FL, USA; ${ }^{2}$ University of Minnesota Medical Center, Minneapolis, MN, USA; ${ }^{3}$ CIBMTR (Center for International Blood and Marrow Transplant Research), Department of Medicine, Medical College of Wisconsin, Milwaukee, WI, USA; 'Division of Biostatistics, Institute for Health and Equity, Medical College of Wisconsin, Milwaukee, WI, USA; '5ivision of Hematology-Oncology, Blood and Marrow Transplantation Program, Mayo Clinic, Jacksonville, FL, USA; ${ }^{6}$ Adult Bone Marrow Transplant, University Hospitals Bristol NHS Trust, Bristol, UK; ' Department of Blood and Marrow Transplant and Cellular Immunotherapy, Moffitt Cancer Center, Tampa, FL, USA; ' ${ }^{2}$ evine Cancer Institute, Atrium Health, Carolinas HealthCare System, Charlotte, NC, USA; 'Blood \& Marrow Transplant Program, Cleveland Clinic Taussig Cancer Institute, Cleveland, OH, USA; ${ }^{10}$ Department of Hematology and Medical Oncology, Winship Cancer Institute, Emory University, Atlanta, GA, USA; ${ }^{11}$ Division of Cell Therapy and Hematology, Department of Medicine, Duke University Medical Center, Durham, NC, USA; ${ }^{12}$ Blood and Cancer Centre, Starship Children's Hospital, Auckland, New Zealand; ${ }^{13}$ Department of Blood and Marrow Transplantation, H. Lee Moffitt Cancer Center and Research Institute, Tampa, FL, USA; ${ }^{14}$ Department of Stem Cell Transplantation, Division of Cancer Medicine, The University of Texas MD Anderson Cancer Center, TX, USA; ${ }^{15}$ Division of Hematopoietic Stem Cell Transplantation, National Cancer Center Hospital, Tokyo, Japan; ${ }^{16} \mathrm{Blood} \&$ Marrow Transplant Program, Cleveland Clinic Taussig Cancer Institute, Cleveland, OH, USA; ${ }^{17}$ Department of Internal Medicine, Mayo Clinic, MN, USA; ${ }^{18}$ Oncology Center, King Faisal Specialist Hospital and Research Center, Riyadh, Saudi Arabia; ${ }^{19}$ Division of Hematology and Oncology, Center for Cell and Gene Therapy, Baylor College of Medicine, Houston, TX, USA; ${ }^{20}$ Department of Hematology, Inselspital, Bern University Hospital, Switzerland; ${ }^{21}$ Markey Cancer Center, University of Kentucky, Lexington, KY, USA; ${ }^{22}$ Loyola University Medical Center, Maywood, IL, USA; ${ }^{23}$ University of Kansas Medical Center, Westwood, KS, USA; ${ }^{24}$ City of Hope

Comprehensive Cancer Center, Duarte, CA, USA; ${ }^{25}$ University of Miami, Miami, FL, USA; ${ }^{26}$ Division of Blood and Marrow Transplantation, Stanford University, Stanford, CA, USA; ${ }^{27}$ Division of Hematology and Oncology, Washington University School of Medicine, St. Louis, MO, USA; ${ }^{28}$ Department of Laboratory Medicine, Karolinska Institutet, Stockholm, Sweden; ${ }^{29}$ Centre for Clinical Research Sormland, Uppsala University, Uppsala, Sweden; ${ }^{30}$ Vanderbilt University Medical Center, Nashville, TN, USA; ${ }^{31}$ Department of Pediatric Hematology, Oncology and Bone Marrow Transplant, British Columbia's Children's Hospital, The University of British Columbia, Vancouver, British Columbia, Canada; ${ }^{32}$ Department of Medical Oncology and Hematology, CancerCare Manitoba, Winnipeg, Manitoba, Canada; ${ }^{33}$ Tom Baker Cancer Centre, Calgary, Alberta, Canada; ${ }^{34}$ Division of Hematology/Oncology, Department of Medicine, Vanderbilt University Medical Center, Nashville, TN, USA; ${ }^{35}$ Department of
Ferrata Storti Foundation

Haematologica 2020

Volume 105(5):1329-1338

\section{Correspondence:}

ALEKSANDR LAZARYAN

aleksandr.lazaryan@moffitt.org

Received: March 12, 2019.

Accepted: September 20, 2019.

Pre-published: September 26, 2019.

doi:10.3324/haematol.2019.220756

Check the online version for the most updated information on this article, online supplements, and information on authorship \& disclosures: www.haematologica.org/content/105/5/1329

\section{(C)2020 Ferrata Storti Foundation}

Material published in Haematologica is covered by copyright. All rights are reserved to the Ferrata Storti Foundation. Use of published material is allowed under the following terms and conditions:

https://creativecommons.org/licenses/by-nc/4.0/legalcode. Copies of published material are allowed for personal or internal use. Sharing published material for non-commercial purposes is subject to the following conditions: https://creativecommons. org//icenses/by-nc/4.0/legalcode, sect. 3. Reproducing and sharing published material for commercial purposes is not allowed without permission in writing from the publisher. 
Hematology/Oncology, Isala Clinic, Zwolle, the Netherlands; ${ }^{36}$ Division of Pediatric Hematology, Oncology and Stem Cell Transplantation, Department of Pediatrics, New York Medical College, Valhalla, NY, USA; ${ }^{37}$ Loyola University Chicago Stritch School of Medicine, Maywood, IL, USA; ${ }^{38}$ The Fred and Pamela Buffett Cancer Center, University of Nebraska Medical Center, Omaha, NE, USA; ${ }^{39}$ The Children's Hospital at TriStar Centennial and Sarah Cannon Research Institute, Nashville, TN, USA; ${ }^{40}$ Division of Hematology, Oncology and Blood \& Marrow Transplantation, Children's Hospital Los Angeles, University of Southern California Keck School of Medicine, Los Angeles, CA, USA; ${ }^{41}$ Section of Hematology/Oncology, Department of Internal Medicine, Louisiana State University Health Shreveport, Shreveport, LA, USA; ${ }^{2}$ Division of Hematologic Malignancies and Cellular Therapy, Duke University, Durham, NC, USA; ${ }^{43}$ Department of Hematology/Oncology, Mayo Clinic, Phoenix, AZ, USA; ${ }^{44}$ Department of Hematology \& Hematopoietic Cell Transplantation, City of Hope, Duarte, CA, USA; ${ }^{45}$ Translational Cell Therapy Group, CLINTEC ( Clinical Science, Intervention and Technology), Karolinska Institutet, Stockholm Sweden; ${ }^{46}$ Academische Ziekenhuis Maastricht, Maastricht, the Netherlands; ${ }^{47}$ Mayo Clinic Florida, Jacksonville, FL, USA; ${ }^{48}$ University of Chicago Medicine, Chicago, IL, USA; ${ }^{9} \mathrm{~B}$ Blood \& Marrow Transplant Center, Florida Hospital Medical Group, Orlando, FL, USA; ${ }^{50}$ UCLA Medical Center, Los Angeles, CA, USA; ${ }^{51}$ The Sidney Kimmel Comprehensive Cancer Center at Johns Hopkins, Baltimore, MD, USA; ${ }^{22}$ QE II Health Sciences Centre, Dalhousie University, Halifax, Nova Scotia, Canada; ${ }^{53}$ Hospital Vall d'Hebron, Barcelona, Spain; ${ }^{54}$ Rush University Medical Center, Chicago, IL, USA; ${ }^{55}$ Christian Medical College, Vellore, India; ${ }^{56}$ Blood and Marrow Transplantation Program, Division of Hematology/Oncology, Department of Internal Medicine, The University of Michigan Medical School, Ann Arbor, MI, USA; ${ }^{57}$ Department of Hematologic Oncology and Blood Disorders, Levine Cancer Institute, Atrium Health, Charlotte, NC, USA; ${ }^{58}$ Division of Hematology-Oncology, Indiana University School of Medicine, Indianapolis, IN, USA; ${ }^{59} \mathrm{National}$ Cancer Institute (NCI), Rockville, MD, USA; ${ }^{60} \mathrm{New}$ York Presbyterian Hospital/Columbia University Medical Center, New York, NY, USA; ${ }^{61}$ UF Health Shands Children's Hospital, Gainesville, FL, USA; ${ }^{62}$ Department of Advanced Medicine, Nagoya University Hospital, Nagoya, Japan; ${ }^{63}$ Department of Hematology and Oncology, Dokkyo Medical University, Tochigi, Japan; ${ }^{64}$ Division of Hematology/Oncology/Cell Therapy, Rush University, Chicago, IL, USA; ${ }^{65}$ Memorial Sloan Kettering Cancer Center, New York, NY, USA; ${ }^{66}$ Case Western Reserve University, Cleveland, OH, USA; ${ }^{67}$ Division of Medical Oncology, University of Washington and Clinical Research Division, Fred Hutchinson Cancer Research Center, Seattle, WA, USA; ${ }^{68}$ Department of Medicine, Seidman Cancer Center, University Hospitals Case Medical Center, Cleveland, OH, USA; ${ }^{9}$ Division of Hematology and Transplant Center, Mayo Clinic Rochester, Rochester, MN, USA; ${ }^{70}$ Blood and Marrow Transplant Program, University of Minnesota Medical Center, Minneapolis, MN, USA and ${ }^{71}$ Division of Hematology, Oncology and Transplantation, Department of Medicine, University of Minnesota Medical Center, Minneapolis, MN, USA.

ABSTRACT

C ytogenetic risk stratification at diagnosis has long been one of the most useful tools to assess prognosis in acute lymphoblastic leukemia (ALL). To examine the prognostic impact of cytogenetic abnormalities on outcomes after allogeneic hematopoietic cell transplantation, we studied 1731 adults with Philadelphia-negative ALL in complete remission who underwent myeloablative or reduced intensity/nonmyeloablative conditioning transplant from unrelated or matched sibling donors reported to the Center for International Blood and Marrow Transplant Research. A total of 632 patients had abnormal conventional metaphase cytogenetics. The leukemia-free survival and overall survival rates at 5 years after transplantation in patients with abnormal cytogenetics were $40 \%$ and $42 \%$, respectively, which were similar to those in patients with a normal karyotype. Of the previously established cytogenetic risk classifications, modified Medical Research Council-Eastern Cooperative Oncology Group score was the only independent prognosticator of leukemia-free survival $(P=0.03)$. In the multivariable analysis, monosomy 7 predicted post-transplant relapse [hazard ratio $(\mathrm{HR})=2.11 ; 95 \%$ confidence interval (95\% CI): 1.04-4.27] and treatment failure $(\mathrm{HR}=1.97 ; 95 \%$ CI: 1.20-3.24). Complex karyotype was prognostic for relapse (HR=1.69; 95\% CI: 1.06-2.69), whereas t(8;14) predicted treatment failure ( $\mathrm{HR}=2.85$; $95 \%$ CI: 1.35-6.02) and overall mortality (HR=3.03; 95\% CI: 1.44-6.41). This large study suggested a novel transplant-specific cytogenetic scheme with adverse [monosomy 7 , complex karyotype, del(7q), t(8;14), t(11;19), del(11q), tetraploidy/near triploidy], intermediate (normal karyotype and all other abnormalities), and favorable (high hyperdiploidy) risks to prognosticate leukemia-free survival $(P=0.02)$. Although some previously established high-risk Philadelphia-negative cytogenetic abnormalities in ALL can be overcome by transplantation, monosomy 7 , complex karyotype, and $t(8 ; 14)$ continue to pose significant risks and yield inferior outcomes.

\section{Introduction}

Allogeneic hematopoietic cell transplantation (HCT) is a potentially curative therapy for patients with acute lymphoblastic leukemia (ALL). Risk stratification of ALL varies across studies and generally includes a spectrum of demographic (e.g., age), clinical (e.g., white blood cell count, minimal residual disease, steroid sensitivity), phenotypic (B-versus T-cell origin), and cytogenetic characteristics. Several cytogenetic risk stratification schemes have been developed and are used as prognostic tools at diag- nosis of ALL to guide treatment decisions. However, most prior studies focusing on the prognostic significance of cytogenetics in ALL were influenced by inclusion of patients with Philadelphia chromosome-positive $\left(\mathrm{Ph}^{+}\right) \mathrm{B}$ ALL and defined for patients who received conventional chemotherapies.

Pivotal Medical Research Council-Eastern Cooperative Oncology Group (MRC-ECOG) and Southwest Oncology Group (SWOG) clinical trials identified commonly recognized $\mathrm{Ph}$-negative $\left(\mathrm{Ph}^{-}\right)$cytogenetic risks, including KMT2A (MLL) translocations at 11q23 associated with 
$\mathrm{t}(4 ; 11)(\mathrm{q} 21 ; \mathrm{q} 23)$, complex karyotype, t(8;14)(q24;q32), low hypodiploidy, or near triploidy, among others. ${ }^{1}$ However, only a subset of $\mathrm{Ph}^{-}$patients underwent allogeneic HCT in those trials. Thus, the applicability of existing cytogenetic risk classifications for allogeneic transplant recipients with ALL remains uncertain due to the relatively low frequency of specific $\mathrm{Ph}^{-}$cytogenetic abnormalities and the modest size of prior studies. In a single-center retrospective cohort study of 333 allograft recipients with ALL, cytogenetic risk did not predict survival after allogeneic HCT. ${ }^{2}$ Notably, in that study $\mathrm{Ph}^{+}$patients accounted for the majority of patients in the poor-risk cytogenetic group, and the cytogenetic risk scheme used was chosen arbitrarily. Another study on allogeneic HCT in Ph- ALL ( $n=373$ ), conducted in Japan, found no difference in overall survival between patients with high-risk $[\mathrm{t}(4 ; 11), \mathrm{t}(8 ; 14)$, low hypodiploidy, and complex karyotype] and standard-risk cytogenetics. ${ }^{3}$ A more recent analysis of $\mathrm{Ph}^{-} \mathrm{B}$-ALL patients from GRAALL clinical trials identified $\mathrm{t}(4 ; 11) / K M T 2 A-A F F 1$ and $\mathrm{t}(\mathrm{v} ; 14 \mathrm{q} 32) / I G H$ as markers of poor clinical outcome; however, only a third of the trial patients underwent allogeneic HCT in first complete remission. ${ }^{4}$

In view of the conflicting prior data, we analyzed Center for International Blood and Marrow Transplant Research (CIBMTR) registry data to determine the prognostic impact of individual conventional (G-banding) cytogenetic abnormalities and major previously established $\mathrm{Ph}^{-}$cytogenetic risk classifications (Table 1) on outcomes of allogeneic HCT. We also developed an allogeneic HCT-specific cytogenetic classification of $\mathrm{Ph}$ ALL for prediction of post-transplant relapse and survival.

\section{Methods}

\section{Data source}

Study data were obtained from the CIBMTR registry which is a voluntary network of over 450 blood and marrow transplant centers in the USA and around the world. Participating centers contributed detailed transplant-related information longitudinally to the centralized data management and statistical centers at the Medical College of Wisconsin (Milwaukee, WI, USA) and the National Marrow Donor Program (NMDP) (Minneapolis, MN, USA). Like all observational research conducted by the CIBMTR, this study adhered to strict federal regulations for the protection of human research subjects. Protected health information used in this study was collected and maintained in CIBMTR's capacity as a Public Health Authority under the Health Insurance Portability Accountability (HIPAA) Privacy Rule.

Table 1. Major established cytogenetic risk classifications of Philadelphia chromosome-negative acute lymphoblastic leukemia.

\begin{tabular}{|c|c|c|c|}
\hline Study & Design highlights & Risk group & Cytogenetic abnormalities \\
\hline \multirow[t]{3}{*}{$\begin{array}{l}\text { MRC-ECOG (Moorman et al. } \\
\text { Blood 2007) }\end{array}$} & \multirow{3}{*}{$\begin{array}{l}\text { - Randomized phase III } \\
\text { - } 796 \text { pts with abnormal } \\
\text { cytogenetics } \\
\text { - } 310 \text { alloHCT }\end{array}$} & Poor & $\begin{array}{l}\mathrm{t}(4 ; 11), \mathrm{t}(8 ; 14)^{*} \text {, complex* }(\geq 5 \text { abnormalities without } \\
\text { translocations), low hypodiploidy }(30-39 \mathrm{chr}) / \text { near triploidy }(60-78 \mathrm{chr})^{*}\end{array}$ \\
\hline & & Other & All other karyotypes \\
\hline & & Good & High hyperdiploidy (>50), del(9p) \\
\hline \multirow[t]{4}{*}{$\begin{array}{l}\text { Modified MRC-ECOG } \\
\text { (Pullarkat et al. Blood 2008) }\end{array}$} & \multirow{4}{*}{$\begin{array}{l}\text { - Randomized phase III } \\
\text { - } 140 \text { pts with evaluable } \\
\text { cytogenetics } \\
\text { - Re-classified by MRC-ECOG } \\
\text { - } 19 \text { alloHCT }\end{array}$} & Very high & $\begin{array}{l}\mathrm{t}(4 ; 11), \mathrm{t}(8 ; 14) \text {, complex ( } \geq 5 \text { abnormalities without } \\
\text { translocations), low hypodiploidy ( } 30-39 \mathrm{chr}) / \text { near triploidy ( } 60-78 \mathrm{chr} \text { ) }\end{array}$ \\
\hline & & High & $\begin{array}{l}\text { Other 11q23/MLL, monosomy } 7^{\S} \text {, del }(7 \mathrm{p}),+8^{\S}, \mathrm{t}(1 ; 19) \text { or } \mathrm{t}(17 ; 19) \text {, } \\
\mathrm{t}(5 ; 14)\end{array}$ \\
\hline & & Intermediate & $\begin{array}{l}\text { Normal diploid, low hyperdiploidy ( } 47-50 \mathrm{chr}) \text {, abnormal } 11 \mathrm{q} \text { (not } \\
M L L) \text {, del }(6 \mathrm{q}) \text {, del( } 17 \mathrm{p}) \text {, del }(9 \mathrm{p}) \text {, del( } 12 \mathrm{p}) \text {, del }(13 \mathrm{q}) \text {, t14q32, } \\
\mathrm{t}(10 ; 14) \text {, tetraploidy }(>80 \mathrm{chr}) \text {, or any karyotype abnormalities not } \\
\text { identified with a different risk group }\end{array}$ \\
\hline & & Standard & High hyperdiploidy ( $>50 \mathrm{chr}$ ) \\
\hline \multirow{3}{*}{$\begin{array}{l}\text { SWOG (Pullarkat et al. } \\
\text { Blood 2008) }\end{array}$} & \multirow{3}{*}{$\begin{array}{l}\text { - Randomized phase III trial } \\
\text { - } 140 \text { pts with evaluable } \\
\text { cytogenetics } \\
\text { - } 19 \text { alloHCT }\end{array}$} & Unfavorable & Monosomy $7,+8$, and 11q23/MLL gene rearrangements \\
\hline & & Miscellaneous & Any other abnormal karyotype \\
\hline & & Normal & Normal karyotype \\
\hline \multirow[t]{3}{*}{$\begin{array}{l}\text { NILG-ALL (Bassan et al. } \\
\text { Blood 2009) }\end{array}$} & \multirow[t]{3}{*}{$\begin{array}{l}\text { - Phase II } \\
\text { - } 276 \text { with evaluable cytogenetics }\end{array}$} & Adverse & $\begin{array}{l}\mathrm{t}(4 ; 11) \text { and/or MLL-AF4, }+8 \text {, near triploidy, low hypodiploidy, } \\
\text { complex ( } \geq 3 \text { abnormalities), del }(6 q), \mathrm{t}(8 ; 14)\end{array}$ \\
\hline & & Non-adverse & $\begin{array}{l}\mathrm{t}(1 ; 19) \text { and/or E2A-PBXI, hyperdiploid, other karyotype } \\
\text { abnormalities not identified with a different risk group }\end{array}$ \\
\hline & & Normal & Normal karyotype \\
\hline \multirow[t]{2}{*}{$\begin{array}{l}\text { North UK (Moorman et al. } \\
\text { Blood 2010) }\end{array}$} & \multirow[t]{2}{*}{$\begin{array}{l}\text { - Observational } \\
\text { - } 292 \text { pts with evaluable cytogenetics }\end{array}$} & Poor & $\begin{array}{l}\mathrm{t}(4 ; 11), \mathrm{t}(8 ; 14), \mathrm{t}(14 ; 18) \text {, complex ( } \geq 5 \text { abnormalities without } \\
\text { translocations), low hypodiploidy ( } 30-39 \mathrm{chr}) / \text { near triploidy }(60-78 \mathrm{chr} \text { ) }\end{array}$ \\
\hline & & Standard & All other karyotypes \\
\hline \multirow{3}{*}{$\begin{array}{l}\text { GIMEMA } 0496 \text { (Mancini et al. } \\
\text { Blood 2005) }\end{array}$} & \multirow{3}{*}{ - Phase II 282 pts with evaluable cytogenetics } & High & $\mathrm{t}(4 ; 11), \mathrm{t}(1 ; 19)$ \\
\hline & & Intermediate & del(6q) and other karyotypes \\
\hline & & Standard & normal karyotype, del(9p) \\
\hline
\end{tabular}

MRC-ECOG: Medical Research Council-Eastern Cooperative Oncology Group;SWOG: Southwest Oncology Group; NILG: Northern Italy Leukemia Group; GIMEMA: Gruppo Italiano Malattie EMatologiche dell'Adulto; alloHCT: allogeneic hematopoietic cell transplantation; pts: patients; chr: chromosomes; $M L L$ : mixed lineage leukemia *Independent predictors. ${ }^{\circledR}$ Unfavorable by Cancer and Leukemia Group B classification. 


\section{Selection of patients}

The initial study population included 3,275 adults (age $\geq 16$ years) with $\mathrm{Ph}^{-} \mathrm{ALL}$ in first or second complete remission (CR1 or CR2, corresponding to morphological remission with $<5 \%$ bone marrow blasts) who underwent allogeneic HCT between 19952011 and whose data were reported to the CIBMTR. Further restriction of the study population to the recipients of HLAmatched sibling and unrelated donor peripheral blood or bone marrow allografts (with consent to submit at least 100 days of post-transplant research reports) resulted in 2,903 eligible study participants. The CIBMTR data center requested original cytogenetic reports for cases with reportedly abnormal or unknown cytogenetics at either the time of diagnosis or prior to allogeneic HCT. Cytogenetic reports were received from participating centers for 1,013 cases, all of which were reviewed and validated by the study's principal investigators (AL, MD). Data on cytogenetics from the existing CIBMTR records were used for 743 cases for which no original cytogenetic reports were received from the queried centers. For 342 cases $(12 \%)$ with prior CIBMTR cytogenetics status reported as "unknown" or "not tested" the original cytogenetic reports were requested, but not received from the transplant centers. Normal conventional cytogenetic results were confirmed with over $95 \%$ accuracy upon review of all original reports received and the remaining 805 cases with normal cytogenetics were included in the final study sample of 1,099 patients with normal cytogenetics reported. Patients with abnormal conventional cytogenetics $(n=632)$ were included in the study population after review of all available original cytogenetic reports. Thus, a total study population of 1,731 patients from 256 reporting centers and 38 countries was analyzed.

\section{Cytogenetics}

Blood and marrow samples at the time of ALL diagnosis and prior to transplantation were cultured and evaluated for cytogenetic abnormalities by G-banding according to the standard practices of the participating centers. Original cytogenetic data reported to the CIBMTR conformed to the International System of Cytogenetic Nomenclature (ISCN). ${ }^{5}$ According to the ISCN, a clonal abnormality was defined as the presence of a gain of the same chromosome or the presence of the same structural abnormality in $\geq 2$ cells or the loss of the same chromosome in $\geq 3$ cells. A normal conventional cytogenetic result was defined as the absence of clonal abnormalities in at least 20 metaphase cells. Abnormal cytogenetics were classified according to previously established cytogenetic risk classifications for $\mathrm{Ph}^{-} \mathrm{ALL}$ (Table 1). Standard definitions for hypodiploid, hyperdiploid, complex, and monosomal karyotypes were based on the following modal chromosome numbers: (i) low hypodiploidy (30-39 chromosomes), (ii) high hypodiploidy (40-43), (iii) low hyperdiploidy (47-50), (iv) high hyperdiploidy ( $>50)$, (v) near triploidy (60-78), (vi) tetraploidy (>80), (vii) complex with $\geq 5$ abnormalities ${ }^{6.8}$ (adopted here) in the absence of established translocations or ploidy abnormalities; or $\geq 3$ abnormalities used exclusively by the Northern Italy Leukemia Group (NILG) ${ }^{9}$ (Table 1), and (viii) monosomal ( $\geq 2$ autosomal monosomies or a single autosomal monosomy combined with a single structural abnormality). Fluorescence in situ hybridization (FISH) findings and/or other molecular data were available for the minority of patients and were, therefore, only used to validate cytogenetic reports when available.

\section{Statistical analysis}

Individual $\mathrm{Ph}^{-}$cytogenetic abnormalities were included in the analysis if they were detected in $\geq 20$ patients or in $<20$ patients but with previously established prognostic significance in ALL.
Cytogenetic abnormalities included high hyperdiploidy $(\mathrm{n}=29)$, tetraploidy $(n=9)$, near triploidy $(n=6)$, low hypodiploidy $(n=11)$, complex karyotype $(n=51)$, monosomal karyotype $(n=84)$, monosomy $17(n=21), i(17 q)(n=5), \operatorname{del}(17 p)(n=6), t(1 ; 19)(n=33), t(4 ; 11)$ $(n=95), t(8 ; 14)(n=10), t(10 ; 11)(n=8), t(11 ; 19)(n=10), \operatorname{add}(5 q)(n=7)$, $\operatorname{del}(5 q)(n=20), \operatorname{add}(7 p)(n=8), i(7 q)(n=10), \operatorname{add}(12 p)(n=10)$, $\operatorname{del}(12 p)(n=18), t(14 ; 18)(n=6), \operatorname{del}(6 q)(n=48), \operatorname{del}(7 q)(n=7)$, monosomy $7(n=33), \operatorname{add}(9 p)(n=11), \operatorname{del}(9 p)(n=52), i(9 q)(n=17)$, $\operatorname{add}(12 p)(n=10), \operatorname{del}(12 p)(n=18), \operatorname{del}(11 q)(n=18), \operatorname{del}(13 q)(n=12)$, and trisomy $8(n=35)$. Each cytogenetic abnormality was tested individually for its association with post-HCT relapse while adjusted for potential confounders. Statistically significant $(P<0.05)$ clinical factors other than cytogenetics [conditioning regimen, remission status, donor type, and graft-versus-host disease (GvHD) prophylaxis among other potential confounders] were retained in the multivariable Cox proportional hazards model. Abnormalities with a hazard ratio (HR) $\geq 1.4$ for relapse were subsequently grouped as adverse risk; abnormalities with a $\mathrm{HR} \leq 0.6$ for relapse were grouped as favorable, whereas all other abnormalities, and normal cytogenetics, were grouped as intermediate risk. Relapse was used as the primary endpoint for evaluation of individual cytogenetic abnormalities and it was calculated as the cumulative incidence of ALL recurrence with treatment-related mortality as the competing risk. Leukemia-free survival was used as the primary endpoint for evaluation of previously established and study-derived cytogenetic risk classifications and was defined as the time to death or relapse with survivors in continuing complete remission censored at last follow-up. Adjusted probabilities of leukemia-free survival and relapse were calculated using multivariable models, stratified by cytogenetic risk scheme and weighted by the pooled sample proportion value for each prognostic factor. ${ }^{10,11}$ Overall survival was a secondary study endpoint and was defined as the time to death from any cause with surviving patients censored at last follow-up. Treatment failure (1 leukemia-free survival) and overall mortality (1 - overall survival) were used to model all Cox regression HR estimates. SAS version 9.4 (SAS Institute, Cary, NC, USA) and GraphPad Prism version 7.04 were used for all data analysis and graphics.

\section{Results}

\section{Study population and transplant characteristics}

A description of the entire study population and the distribution of the main study variables among patients with abnormal and normal cytogenetics are summarized in Table 2 . The study cohort consisted predominantly of young $(82 \%<45$ years) male $(63 \%)$ patients with B-precursor ALL (69\%). Patients with hyperleukocytosis (white blood cell count $>30 \times 10^{\circ} / \mathrm{L}$ for B-ALL and $>100 \times 10^{9} / \mathrm{L}$ for T-ALL) at the time of initial diagnosis accounted for $22 \%$ of the entire cohort and $57 \%$ of patients underwent allogeneic HCT in CR1 with a median time to achieve CR1 of 6 weeks (range, 1-123).

\section{Post-transplant outcomes classified by established cytogenetic schemes}

Patients with abnormal cytogenetics had 5-year leukemia-free and overall survival rates of $40 \%$ and $42 \%$, respectively, which were similar to those of patients with a normal karyotype (both $P>0.6$ ). The cytogenetic risk categories defined by the MRC-ECOG, SWOG, NILG-ALL, North UK, and GIMEMA 0496 (Table 1) had no prognostic significance for leukemia-free survival, relapse, or overall survival (all $P$-values $>0.15$ ). However, the cytogenetic risk 
Table 2. Patient and transplant characteristics.

\begin{tabular}{|c|c|c|c|}
\hline Variables & All & $\begin{array}{l}\text { Cytogenetics } \\
\text { Abnormal }\end{array}$ & $\begin{array}{l}\text { Cytogenetics } \\
\text { Normal }\end{array}$ \\
\hline Number of patients & 1731 & $632(36.5)$ & $1099(63.5)$ \\
\hline Number of centers & 256 & 178 & 226 \\
\hline Recipient age, median (range), years & $29(16-68)$ & $28(16-65)$ & $29(16-68)$ \\
\hline Gender, female, n (\%) & $636(37)$ & $234(37)$ & $402(37)$ \\
\hline $\begin{array}{l}\text { Recipient race, n (\%) } \\
\text { Caucasian } \\
\text { African-American } \\
\text { Asian } \\
\text { Other }\end{array}$ & $\begin{array}{l}1429(83) \\
42(2) \\
154(9) \\
106(7)\end{array}$ & $\begin{array}{l}534(84) \\
12(2) \\
49(8) \\
37(6)\end{array}$ & $\begin{array}{c}895(81) \\
30(3) \\
105(10) \\
69(6)\end{array}$ \\
\hline Karnofsky score $\geq 90 \%$, n (\%) & $1245(72)$ & $459(73)$ & $786(72)$ \\
\hline $\begin{array}{l}\text { Disease status prior to alloHCT, n (\%) } \\
\text { CR1 } \\
\text { CR2 }\end{array}$ & $\begin{array}{l}990(57) \\
741(43)\end{array}$ & $\begin{array}{l}395(62.5) \\
237(37.5)\end{array}$ & $\begin{array}{l}595(54) \\
504(46)\end{array}$ \\
\hline Time to CR1, median (range), weeks & $6(1-123)$ & $5(2-123)$ & $6(1-113)$ \\
\hline $\begin{array}{l}\text { Time from CR1 to alloHCT', median } \\
\text { (range), months }\end{array}$ & $3(<1-16)$ & $3(<1-13)$ & $4(<1-16)$ \\
\hline $\begin{array}{l}\text { Time from CR1 to relapse }{ }^{2} \text {, } \\
\text { median (range), months }\end{array}$ & $20(<1-111)$ & $18(<1-103)$ & $21(1-111)$ \\
\hline $\begin{array}{l}\text { ALL lineage, n (\%) } \\
\text { B-ALL } \\
\text { T-ALL } \\
\text { Unknown }\end{array}$ & $\begin{array}{l}1197(69) \\
393(23) \\
141(8)\end{array}$ & $\begin{array}{l}474(75) \\
121(19) \\
37(6)\end{array}$ & $\begin{array}{c}723(66) \\
272(25) \\
104(9)\end{array}$ \\
\hline $\begin{array}{l}\text { Hyperleukocytosis at diagnosis, } \mathrm{n}(\%) \\
\text { B-ALL (>30x10 } \mathrm{WBC} / \mathrm{L}) \\
\text { T-ALL }\left(>100 \times 10^{9} \mathrm{WBC} / \mathrm{L}\right)\end{array}$ & $\begin{array}{c}299(17) \\
81(5)\end{array}$ & $\begin{array}{c}150(24) \\
31(5)\end{array}$ & $\begin{array}{l}149(14) \\
50(4)\end{array}$ \\
\hline $\begin{array}{l}\text { Extramedullary ALL at diagnosis, n (\%) } \\
\text { CNS } \\
\text { Non-CNS }\end{array}$ & $\begin{array}{l}105(6) \\
202(12)\end{array}$ & $\begin{array}{l}35(6) \\
70(11)\end{array}$ & $\begin{array}{l}70(6) \\
132(12)\end{array}$ \\
\hline $\begin{array}{l}\text { Conditioning intensity, n (\%) } \\
\text { MAC (+TBI) } \\
\text { MAC (-TBI) } \\
\text { NMA/RIC } \\
\text { Unknown }\end{array}$ & $\begin{array}{l}1343(78) \\
254(15) \\
98(6) \\
36(2)\end{array}$ & $\begin{array}{l}522(83) \\
72(11) \\
28(5) \\
10(2)\end{array}$ & $\begin{array}{l}821(75) \\
182(17) \\
70(7) \\
26(2)\end{array}$ \\
\hline $\begin{array}{l}\text { GvHD prophylaxis, n (\%) } \\
\text { Tacrolimus-based } \\
\text { Cyclosporine A-based } \\
\text { T-cell depletion (ex-vivo) }\end{array}$ & $\begin{array}{c}576(33) \\
1000(58) \\
123(7)\end{array}$ & $\begin{array}{c}217(34) \\
350(55) \\
55(9)\end{array}$ & $\begin{array}{l}359(33) \\
650(59) \\
68(6)\end{array}$ \\
\hline $\begin{array}{l}\text { In-vivo T-cell depletion, n (\%) } \\
\text { Alemtuzumab } \\
\text { ATG }\end{array}$ & $\begin{array}{c}46(3) \\
286(17)\end{array}$ & $\begin{array}{c}19(3) \\
99(16)\end{array}$ & $\begin{array}{c}27(2) \\
187(17)\end{array}$ \\
\hline $\begin{array}{l}\text { Graft source, n (\%) } \\
\text { Bone marrow } \\
\text { Peripheral blood }\end{array}$ & $\begin{array}{l}790(46) \\
941(54)\end{array}$ & $\begin{array}{l}281(44) \\
352(46)\end{array}$ & $\begin{array}{l}509(46) \\
590(54)\end{array}$ \\
\hline $\begin{array}{l}\text { Donor type, } \mathrm{n}(\%) \\
\text { HLA-identical sibling } \\
\text { Well-matched unrelated donor } \\
\text { Partially-matched/mismatched } \\
\text { unrelated donor } \\
\text { Other related/unrelated donor }\end{array}$ & $\begin{array}{l}819(47) \\
469(27) \\
357(21) \\
\\
172(10)\end{array}$ & $\begin{array}{l}270(43) \\
188(30) \\
141(22) \\
70(11)\end{array}$ & $\begin{array}{l}549(50) \\
281(26) \\
216(20) \\
102(9)\end{array}$ \\
\hline $\begin{array}{l}\text { Donor/recipient CMV serostatus, n (\%) } \\
\text { Donor+/recipient+ } \\
\text { Donor+/recipient- } \\
\text { Donor-/recipient+ } \\
\text { Donor-/recipient- } \\
\text { Unknown }\end{array}$ & $\begin{array}{l}574(33) \\
193(11) \\
385(22) \\
494(29) \\
85(5)\end{array}$ & $\begin{array}{l}170(27) \\
78(12) \\
143(23) \\
210(33) \\
31(5)\end{array}$ & $\begin{array}{l}404(37) \\
115(10) \\
242(22) \\
284(26) \\
54(5)\end{array}$ \\
\hline $\begin{array}{l}\text { Donor/recipient gender match, n (\%) } \\
\text { Male-male } \\
\text { Male-female }\end{array}$ & $\begin{array}{l}691(40) \\
340(20)\end{array}$ & $\begin{array}{l}256(41) \\
127(20)\end{array}$ & $\begin{array}{l}435(40) \\
213(19)\end{array}$ \\
\hline
\end{tabular}

\begin{tabular}{lccc|} 
Female-male & $401(23)$ & $142(22)$ & $259(24)$ \\
Female-female & $295(17)$ & $107(17)$ & $188(17)$ \\
Unknown & $4(<1)$ & 0 & $4(<1)$ \\
\hline $\begin{array}{l}\text { Year of alloHCT, n (\%) } \\
\text { 1995-2000 }\end{array}$ & $557(32)$ & $194(31)$ & $363(33)$ \\
$2001-2005$ & $604(35)$ & $217(34)$ & $387(35)$ \\
$2006-2011$ & $570(33)$ & $221(35)$ & $349(32)$ \\
Median follow up of survivors & & & \\
(range), months & $75(2-224)$ & $87(3-224)$ & $73(2-218)$ \\
\hline
\end{tabular}

alloHCT: allogeneic hematopoietic cell transplantation; CR1: first complete remission; CR2: second complete remission;ALL: acute lymphoblastic leukemia;WBC: white blood cell; CNS: central nervous system; MAC: myeloablative conditioning; TBI: total body irradiation; NMA non-myeloablative; RIC: reduced-intensity conditioning; HLA: human leukocyte antigen; GvHD: graft-versus-host disease;ATG: antithymocyte globulin; CMV: cytomegalovirus. 'Referred to patients in CR1. ${ }^{2}$ Referred to patients in CR2.

classification defined by the modified MRC-ECOG was significantly associated with both treatment failure (overall $P=0.02$ ) and overall survival (overall $P=0.03$ ) in multivariable analyses adjusted for recipient age, disease status, conditioning intensity, Karnofsky Performance Status, donor type, and GvHD prophylaxis (Figures 1A and 2). Significant associations between the modified MRCECOG classification and major clinical outcomes appeared to be largely driven by the favorable outcomes of patients with standard-risk cytogenetics ( $\mathrm{n}=24)$, all with a high hyperdiploid karyotype. There was no difference between high or very high modified MRC-ECOG cytogenetic risk groups compared to the intermediate group. In contrast, good-risk cytogenetics according to the MRCECOG classification included del( $9 p)$, in addition to high hyperdiploidy, and was not significantly associated with any of the clinical outcomes of interest.

\section{Individual cytogenetic abnormalities: relapse}

Monosomy 7 [HR=2.11; 95\% confidence interval (CI): 1.04-4.27, $P=0.04]$ and complex karyotype ( $\mathrm{HR}=1.69 ; 95 \%$ CI: $1.06-2.69, \quad P=0.03$ ) were both associated with increased risk of relapse in multivariable analysis adjusted for conditioning intensity, ALL remission status prior to transplantation, and monosomal karyotype (Figure 3, Table 3). Patients with high hyperdiploidy had an estimated $54 \%$ lower risk of relapse, whereas those with $\operatorname{del}(7 \mathrm{q})$, $\mathrm{t}(8 ; 14), \mathrm{t}(11 ; 19)$, del(11q), or a tetraploid/near triploid karyotype had a HR of at least $40 \%$ higher for relapse, which did not reach statistical significance (Figure 3 ). The magnitude and strength of associations with relapse for the remaining individual cytogenetic categories, such as trisomy 8, monosomal karyotype, monosomy 17, $\operatorname{del}(17 p) / i(17 p)$, low hypodiploidy, del(6q), t(1;19), t(4;11), and normal karyotype, did not demonstrate any meaningful clinical associations (all HR between 0.6 and 1.4), and none was statistically significant (all $P$-values $>0.1$ ).

A significant interaction was detected between $\mathrm{t}(4 ; 11)$ and pre-transplant remission status $(P<0.001)$ with the adverse impact of $t(4 ; 11)$ on relapse observed only in patients undergoing allogeneic HCT in $\mathrm{CR} 2(\mathrm{HR}=2.82$; 95\% CI: $1.25-6.36, P=0.01$ ), but not in CR1 (HR $=0.86,95 \%$ CI: 0.53-1.41, $P=0.55$ ).

Individual cytogenetic abnormalities: treatment failure

Monosomy 7 (HR=1.97; 95\% CI: 1.20-3.24, $P=0.007$ ) and $\mathrm{t}(8 ; 14)(\mathrm{HR}=2.85 ; 95 \% \mathrm{CI}: 1.35-6.02, P=0.006)$ were 
prognostic for treatment failure after adjustments for recipient age, pre-transplant remission status, conditioning intensity, donor type, and GvHD prophylaxis in multivariable analyses (Table 4). Trends toward increased risk of treatment failure were observed for patients with $\operatorname{del}(7 \mathrm{q}) \quad(\mathrm{HR}=2.16 ; 95 \% \mathrm{CI}: 0.95-4.90, P=0.06)$ and $\operatorname{del}(17 p) / \mathrm{i}(17 \mathrm{q}) \quad(\mathrm{HR}=1.95 ; 95 \% \mathrm{CI}: 0.80-4.75, P=0.1)$. In contrast, patients with high hyperdiploidy ( $\mathrm{HR}=0.62 ; 95 \%$ CI: $0.37-1.04, P=0.07)$ and monosomal karyotype $(\mathrm{HR}=0.73$; 95\% CI: 0.54-1.01, $P=0.05)$ trended toward less risk of treatment failure. Although $\mathrm{t}(4 ; 11)$ was not associated with treatment failure ( $\mathrm{HR}=1.12 ; 95 \% \mathrm{CI}$ : 0.85-1.48, $P=0.41)$ within the entire cohort or in CR1 patients $(n=83)$ (HR=0.98; 95\% CI: 0.72-1.33, $P=0.89$ ), it was associated with a significantly higher risk of treatment failure in CR2 patients $(\mathrm{n}=11) \quad(\mathrm{HR}=2.35$; 95\% CI: 1.25-4.43, $P=0.008)$.

\section{Individual cytogenetic abnormalities: overall mortality}

After adjustment for recipient age ( $\mathrm{HR}=1.55$; 95\% CI: $1.17-2.06, P<0.01$ for age $>55$ years versus $<40$ years),
Karnofsky Performance Status <90 ( $\mathrm{HR}=1.29$; 95\% CI: 1.12-1.48, $P<0.001)$, ALL in CR2 (HR=1.56; 95\% CI: $1.36-$ 1.77, $P<0.001)$, myeloablative conditioning without total body irradiation ( $\mathrm{HR}=1.35$; 95\% CI: 1.13-1.62, $P<0.001)$, mismatched unrelated donor ( $\mathrm{HR}=1.49$; 95\% CI: 1.27$1.76, P<0.001)$, and $\mathrm{GvHD}$ prophylaxis $(\mathrm{HR}=1.41 ; 95 \% \mathrm{CI}$ : 1.11-1.79, $P=0.005$ for non-calcineurin inhibitor- versus tacrolimus-based) in multivariable analysis, only $\mathrm{t}(8 ; 14)$ was associated with higher mortality after allogeneic HCT (HR=3.03; 95\% CI: 1.44-6.41, $P=0.004)$.

\section{Novel allogeneic hematopoietic cell transplantation- specific cytogenetic classification}

Based on the relapse model adjusted for significant clinical factors and individual cytogenetic abnormalities (Figure 3), the following cytogenetic markers with $\mathrm{HR} \geq 1.4$ were categorized as adverse risk $(n=125)$ : monosomy 7, complex karyotype, $\operatorname{del}(7 \mathrm{q}), \mathrm{t}(8 ; 14), \mathrm{t}(11 ; 19)$, del(11q), and tetraploid/near triploid karyotype. Conversely, high hyperdiploidy $(n=29)$ was identified as
A

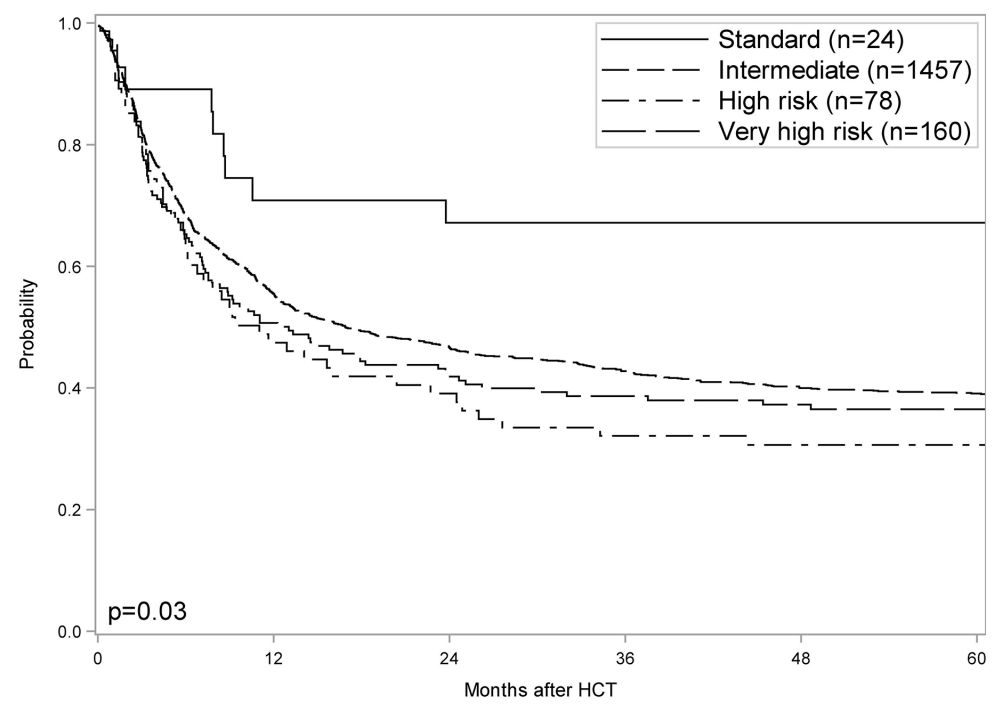

B

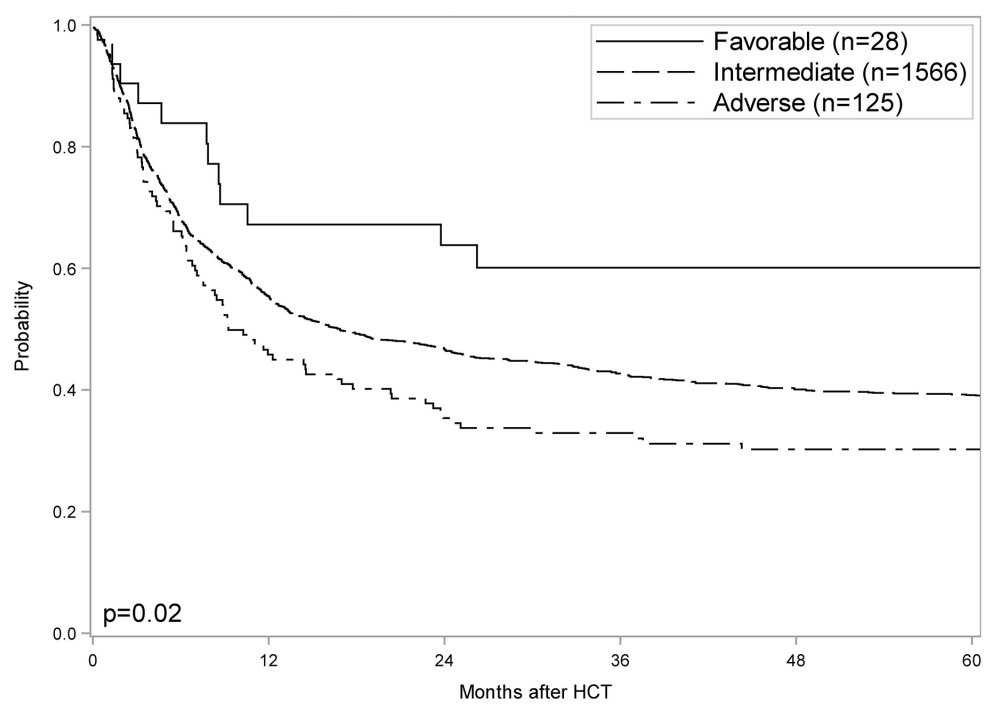

Figure 1. Adjusted leukemia-free survival by cytogenetic risk classifications. (A) Adjusted leukemiafree survival by modified Medical Research Council - Eastern Cooperative Oncology Group cytogenetic risk classification. (B) Adjusted leukemia-free survival by Center for International Blood and Marrow Transplant Research acute lymphoblastic leukemia risk classification. HCT: hematopoietic cell transplantation. 
the sole cytogenetic abnormality with a $H R \leq 0.6$ for relapse, and was categorized as favorable risk. The remaining cytogenetic markers, including normal cytogenetics, were categorized as intermediate risk ( $n=1566)$. This novel allogeneic HCT-specific cytogenetic risk classification (hereafter called CIBMTR ALL risk) was found to be prognostic for both post-transplant relapse (Online Supplementary Figure S1) and leukemia-free survival (logrank $P=0.04$ ) (Figure $1 \mathrm{~B}$ ). Furthermore, in the multivariable Cox proportional hazards model adjusted for recipient age, pre-transplant remission status, conditioning intensity, Karnofsky Performance Status, donor type, and GvHD prophylaxis, patients with CIBMTR adverse-risk cytogenetics had a higher risk of treatment failure ( $\mathrm{HR}=1.26$; 95\% CI: 1.01-1.57, $P=0.04$ ), and those with favorable risk had a lower risk ( $\mathrm{HR}=0.6$; 95\% CI: 0.351.02, $P=0.06)$ compared to those with intermediate-risk cytogenetics (Table 5). There was a significantly greater risk of treatment failure in those with adverse versus favorable risk cytogenetic abnormalities ( $\mathrm{HR}=2.10$; 95\% CI: $1.19-3.70, P=0.01)$. Similarly, there was a significantly greater risk of overall mortality in patients with adverse versus favorable risk cytogenetic abnormalities $(\mathrm{HR}=1.91$; 95\% CI: 1.08-3.38, $P=0.03)$.

\section{Discussion}

This large CIBMTR analysis of allogeneic HCT recipients with $\mathrm{Ph}^{-}$ALL defined a cytogenetic classification specific to allogeneic transplantation. Of the established

Table 3. Multivariable model of prognostic factors for post-transplant relapse.

\begin{tabular}{lccc} 
Factors & N & HR $(95 \%$ CI $)$ & P-value \\
Conditioning regimens & \multicolumn{3}{c}{} \\
MAC (+TBI) & 1334 & 1.0 & \\
MAC (-TBI) & 253 & $1.54(1.22-1.96)$ & $<0.001$ \\
RIC/NMA & 96 & $1.9(1.38-2.61)$ & $<0.001$ \\
Remission status pre-alloHCT & & \\
CR1 & 986 & 1.0 & \\
CR2 & 733 & $1.71(1.44-2.04)$ & $<0.001$ \\
\hline Cytogenetics & & & \\
Complex karyotype* & 51 & $1.69(1.06-2.69)$ & 0.03 \\
Monosomy 7* & 33 & $2.11(1.04-4.27)$ & 0.04 \\
\hline
\end{tabular}

N: number; HR: hazard ratio; 95\% CI: 95\% confidence interval; MAC: myeloablative conditioning;TBI: total body irradiation; RIC: reduced-intensity conditioning; NMA: non-myeloablative; alloHCT: allogeneic hematopoietic cell transplantation; CR1: first complete remission; CR2: second complete remission. *Adjusted for monosomal karyotype.
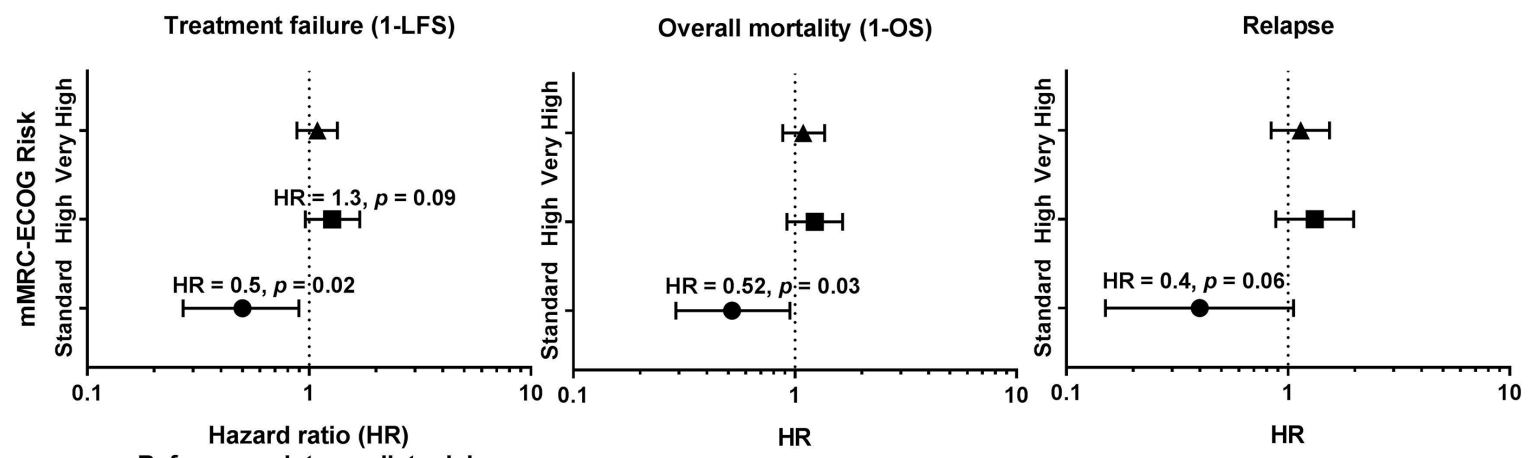

Reference $=$ Intermediate risk

Figure 2. Cytogenetic risks by modified Medical Research Council - Eastern Cooperative Oncology Group cytogenetic risk classification and post-transplant outcomes. All multivariable models were adjusted for recipient age, disease status, conditioning intensy, Karnofsky Performance Status, donor type and graft-versushost disease prophylaxis. mMRC-ECOG: modified Medical Research Council-Eastern Cooperative Oncology Group classification with its three cytogenetic risk groups on $\mathrm{Y}$-axis, relative to the Intermediate risk (reference with $\mathrm{HR}=1$ ) on $\mathrm{X}$-axis; LFS: leukemia-free survival; OS: overall survival.

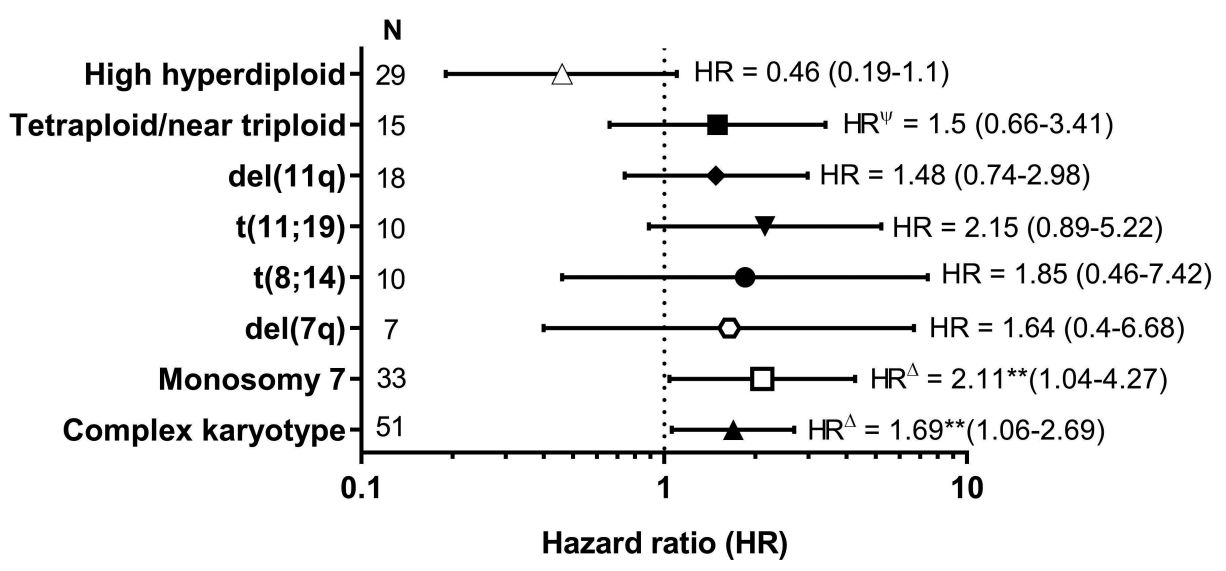

Figure 3. Forest plots of cytogenetic markers associated with post-transplant relapse. All hazard ratios (HR) and corresponding $95 \%$ confidence intervals (Cl) are adjusted for conditiong intensity and remisssion status; CK: complex karyotype; N: sample size of carriers of each cytogenetic marker. * Defined as $40 \%$ risk increase or decrement; ** Markers with $P<0.05$; ${ }^{w}$ Adjusted also for complex karyotype. ${ }^{\wedge}$ Adjusted also for monosomal karyotype. 
major ALL cytogenetic risk schemes, only the modified MRC-ECOG classification could be validated in our dataset for its association with post-transplant outcomes. The association of the modified MRC-ECOG classification was largely explained by favorable outcomes for patients with high hyperdiploidy, a factor known to be associated with better outcomes. ${ }^{12,13}$ While a few individual high-risk cytogenetic abnormalities maintained their prognostic relevance for recipients of allogeneic HCT, many others had no significant prognostic influence on the transplant outcomes. Thus, the aggregate effects of previously established high or very high risk cytogenetic groups defined by MRC-ECOG, SWOG, NILG-ALL, North UK, and GIMEMA 0496 were overcome by allogeneic HCT and did not predict the outcomes of the transplant recipients. High-risk cytogenetic abnormalities including trisomy 8 , low hypodiploidy, $\mathrm{t}(1 ; 19)$, del(6q) could be overcome, in part, by the graft-versus-leukemia effect of allogeneic HCT, and thus, were not unfavorable in this analysis. In contrast to findings in acute myeloid leukemia ${ }^{14,15}$ and recently reported cases of ALL, ${ }^{4,16}$ in our dataset and elsewhere, ${ }^{17}$ monosomal karyotype did not predict poor post-transplant outcomes for $\mathrm{Ph}^{-}$ALL. Similarly, our analysis did not confirm the adverse effect of $t(4 ; 11)$ on relapse or leukemia-free survival among all carriers of this well-known cytogenetic risk, but uncovered a differential effect of $t(4 ; 11)$ on transplant outcomes which was modified by pre-transplant disease status. Nevertheless, given the relatively small subset of patients with $t(4 ; 11)$ in CR2, the results of our post-hoc analysis should be interpreted with caution. Moreover, the infrequency of CR2 allografts in patients with $t(4 ; 11)$ may reflect intrinsic difficulty for those patients to effectively maintain maintain subsequent remissions. A recent comparison of allograft recipients with $\mathrm{t}(4 ; 11)$ and normal karyotype in CR1 demonstrated relatively favorable survival of patients with $t(4 ; 11)$ and especially those with undetectable pretransplant minimal residual disease. ${ }^{18}$ Allogeneic HCT in CR1 for adult ALL patients with $\mathrm{t}(4 ; 11)$ remains valuable. ${ }^{19}$

High-risk cytogenetic abnormalities found in this study included $\mathrm{t}(8 ; 14)$, complex karyotype, and monosomy 7 , previously known poor-risk categories in major classification schemes, excluding GIMEMA 0496 (Table 1). Patients with these high-risk cytogenetic abnormalities were predominantly young adults, most of whom received myeloablative conditioning and still had poor outcomes, thus confirming the high-risk nature of cytogenetic abnormalities.

The $t(8 ; 14)$ is a rare recurrent abnormality among patients with $\mathrm{ALL}^{20.23}$ and has been associated with a poor outcome. It was observed in ten allogeneic HCT recipients (median age, 21) who had a nearly 3-fold significantly lower leukemia-free survival in our cohort. In addition to the $I G H-M Y C$ fusion resulting from the $\mathrm{t}(8 ; 14)$, other $I G H$ translocations involving $B C L 2$ (when present together

Table 4. Multivariable model of prognostic factors for post-transplant treatment failure.

\begin{tabular}{|c|c|c|c|}
\hline Factors & N & HR (95\% CI) & P-value \\
\hline \multicolumn{4}{|c|}{ Age, years } \\
\hline $16-39$ & 1270 & 1.0 & \\
\hline $40-55$ & 363 & 1.21 (1.04-1.41) & 0.02 \\
\hline $55+$ & 86 & $1.42(1.07-1.88)$ & 0.01 \\
\hline \multicolumn{4}{|c|}{ Remission status pre-alloHCT } \\
\hline CR1 & 986 & 1.0 & \\
\hline CR2 & 733 & $1.53(1.34-1.74)$ & $<0.001$ \\
\hline
\end{tabular}

Conditioning regimens

\begin{tabular}{lccc} 
MAC (+TBI) & 1334 & 1.0 & \\
MAC (-TBI) & 253 & $1.4(1.18-1.66)$ & $<0.001$ \\
MAC (+TBI) & 1334 & 1.0 & \\
RIC/NMA & 96 & $1.26(0.97-1.64)$ & 0.09 \\
\hline
\end{tabular}

Performance status

$\begin{array}{lll}\mathrm{KPS} \geq 90 & 1234 & 1.0\end{array}$

$\mathrm{KPS}<90 \quad 423 \quad 1.32(1.15-1.52) \quad<0.001$

\begin{tabular}{lccc} 
Donor type & & & \\
MSD & 818 & 1.0 & \\
Matched URD & 464 & $1.06(0.9-1.24)$ & 0.49 \\
Mismatched URD & 351 & $1.43(1.21-1.68)$ & $<0.001$ \\
Other RD/URD & 86 & $1.36(1.02-1.81)$ & 0.03 \\
\hline
\end{tabular}

GvHD prophylaxis

$\begin{array}{lccc}\text { Tac-based } & 569 & 1.0 & \\ \text { CsA-based } & 996 & 1.11(0.96-1.28) & 0.15 \\ \text { Other } & 134 & 1.39(1.1-1.75) & 0.006 \\ \text { Cytogenetics } & & & \\ \text { t(8;14) } & 10 & 2.85(1.35-6.02) & 0.006 \\ \text { Monosomy } 7^{*} & 33 & 1.97(1.2-3.24) & 0.007\end{array}$

N: number; HR: hazard ratio; 95\% CI: 95\% confidence interval; alloHCT: allogeneic hematopoietic cell transplantation; CR1: first complete remission; CR2: second complete remission; MAC: myeloablative conditioning; TBI: total body irradiation; RIC: reduced-intensity conditioning: NMA: non-myeloablative: KPS: Karnofsky Performance Status; MSD: matched sibling donor; RD: related donor; URD: unrelated donor; GvHD: graft-versus-host disease; CSA: cyclosporine. *Adjusted for monosomal karyotype.

Table 5. Novel Center for International Blood and Marrow Transplant Research risk scheme for post-transplant Philadelphia-negative acute lymphoblastic leukemia outcomes

\begin{tabular}{|c|c|c|c|c|}
\hline \multirow[t]{2}{*}{ Cytogenetic risk groups } & \multirow[t]{2}{*}{$\mathbf{N}$} & \multicolumn{3}{|c|}{ HR $(95 \%$ CI)* } \\
\hline & & Treatment failure(1-LFS) & Relapse & Overall mortality (1-0S) \\
\hline Favorable (high hyperdiploidy) & 28 & $0.6(0.35-1.02)$ & $0.39(0.15-1.05)$ & $0.64(0.37-1.08)$ \\
\hline $\begin{array}{l}\text { Intermediate (normal karyotype } \\
\text { and all other abnormalities }\end{array}$ & 1578 & 1.0 (Reference) & 1.0 (Reference) & 1.0 (Reference) \\
\hline $\begin{array}{l}\text { Adverse (monosomy } 7 \text {, complex karyotype, } \\
\text { del(7q), } \mathrm{t}(8 ; 14), \mathrm{t}(11 ; 19) \text {, del(11q), } \\
\text { tetraploidy/near triploidy) }\end{array}$ & 125 & $1.26(1.01-1.57)$ & $1.48(1.09-2.0)$ & $1.22(0.97-1.53)$ \\
\hline Adverse vs. favorable & - & $2.1(1.19-3.7)$ & $3.78(1.36-1.76)$ & $1.91(1.08-3.38)$ \\
\hline
\end{tabular}

HR: hazard ratio; 95\% CI: 95\% confidence interval; LFS: leukemia-free survival; OS: overall survival. *Adjusted for conditioning intensity, disease status prior to transplantation, recipient age, Karnofsky Performance Status, donor type, graft-versus-host disease prophylaxis, as applicable based on the individual models. ${ }^{\circledR}$ Except for those included in the adverse and favorable groups 
with IGH-MYC) and CRLF2 have also been reported to yield poor outcomes. ${ }^{24-26}$

Our study confirmed the previously established unfavorable risk associated with a complex karyotype $e^{6,27}$ after allogeneic HCT. Notably, we observed substantial overlap between complex karyotype, monosomal karyotype, and other common abnormalities, mandating careful data analysis and interpretation of complex cytogenetics in future studies.

Monosomy 7 was consistently associated with worse post-transplant outcomes in this and prior studies. ${ }^{8}$ Multiple mechanisms have been proposed to explain the effects of monosomy 7 on leukemogenesis including, but not limited to, loss of tumor suppressor genes, haploinsufficiency, or monoallelic loss of IKZF1, an important adverse prognostic marker in B-cell ALL which is localized to chromosome $7 p^{28,29}$ Haploinsufficient deletions of IKZF1 are enriched among $\mathrm{Ph}^{-}$ALL cases and associated with inferior survival. ${ }^{30}$

Our observed higher risk of relapse among allogeneic HCT recipients with $t(11 ; 19)$ was also consistent with the previously reported poor survival of ALL patients with $\mathrm{t}(11 ; 19)(\mathrm{q} 23 ; \mathrm{p} 13.3){ }^{31}$

We propose an allogeneic HCT-specific cytogenetic risk classification for $\mathrm{Ph}^{-}$ALL separating patients into three prognostic risk categories based on the presence of monosomy 7, del(7q), t(8;14), t(11;19), del(11q), complex, tetraploid/near triploid, and high hyperdiploid karyotypes (Table 5). This novel CIBMTR ALL risk classification of $\mathrm{Ph}^{-}$patients treated with allogeneic HCT is directly relevant to pre-HCT decision-making and might help in stratifying clinical trial candidates undergoing allogeneic HCT for $\mathrm{Ph}^{-} \mathrm{ALL}$.

Unfortunately we could not account in our analysis for pre-transplant minimal residual disease (MRD), defined by flow cytometry or FISH/molecular testing. Pre-transplant MRD has been important in predicting ALL relapse and future research should combine cytogenetic classifications with pre-transplant MRD status. Pretreatment complex karyotype and low hypodiploidy/near-triploidy portended poor survival after adjustment for MRD in a recent single-institution study. ${ }^{27}$ Our analysis validated other established patient- and transplant-related prognostic factors and thereby confirmed the additional importance of the cytogenetic groupings. As most patients in this cohort received allografts with myeloablative conditioning, future validation of the CIBMTR ALL risk scheme among recipients treated with reduced intensity conditioning will test this prognostic tool in older and/or less fit ALL patients.

Our study focused on the transplant period preceding Food and Drug Administration approvals and broader use of liposomal vincristine, blinatumomab, inotuzumab ozogamycin, or tisagenlecleucel, and it thereby focused on a more homogeneous patient population with no differen- tial effect on treatment outcomes found according to quinquennial transplant periods from 1995 to 2011.

While many patients with previously established highrisk $\mathrm{Ph}^{-}$cytogenetic abnormalities can benefit from allogeneic HCT, those with monosomy 7, complex karyotype, and $\mathrm{t}(8 ; 14)$ remain at high risk for treatment failure after transplantation. Selective targeting of these and other clinically-defined high-risk cohorts will be necessary to improve post-transplant survival of patients with $\mathrm{Ph}^{-} \mathrm{ALL}$.

\section{Acknowledgments}

The CIBMTR is supported primarily by a public health service grant/cooperative agreement U24CA076518 from the National Cancer Institute (NCI), the National Heart, Lung and Blood Institute (NHLBI) and the National Institute of Allergy and Infectious Diseases (NIAID); grant/cooperative agreement U24HL138660 from the NHLBI and NCI; grant U24CA233032 from the NCI; grants OT3HL147741, R21HL140314 and U01HL128568 from the NHLBI; a contract HHSH250201700006C with Health Resources and Services Administration (HRSA/DHHS); grants N00014-181-2888 and N00014-17-1-2850 from the Office of Naval Research; and grants from *Actinium Pharmaceuticals, Inc.; Adaptive Biotechnologies; *Amgen, Inc.; Anonymous donation to the Medical College of Wisconsin; *Anthem, Inc.; Astellas Pharma US; Atara Biotherapeutics, Inc.; Be the Match Foundation; *bluebird bio, Inc.; Boston Children's Hospital; *Bristol Myers Squibb Co.; *Celgene Corp.; Children's Hospital

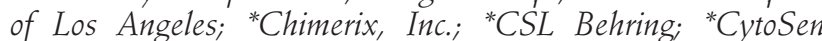
Therapeutics, Inc.; Dana Farber Cancer Institute; *Daiichi Sankyo Co., Ltd.; Fred Hutchinson Cancer Research Center; ${ }^{*}$ Gamida-Cell, Ltd.; Gilead Sciences, Inc.; *GlaxoSmithKline (GSK); HistoGenetics, Inc.; Immucor; Incyte Corporation; Janssen Biotech, Inc.; *Janssen Pharmaceuticals, Inc.; Janssen Scientific Affairs, LLC; *Jazz Pharmaceuticals, Inc.; Karius, Inc.; Karyopharm Therapeutics, Inc.; *Kite, a Gilead Company; *Magenta Therapeutics; Medac GmbH; The Medical College of Wisconsin; Mediware; Merck \& Company, Inc.; *Mesoblast; MesoScale Diagnostics, Inc.; Millennium, the Takeda Oncology Co.; *Miltenyi Biotec, Inc.; Mundipharma EDO; National Marrow Donor Program; Novartis Oncology; Novartis Pharmaceuticals Corporation; *Omeros Corporation; *Oncoimmune, Inc.; PCORI; *Pfizer, Inc.; *Phamacyclics, LLC; PIRCHE AG; *Regeneron Pharmaceuticals, Inc.; REGiMMUNE Corp.; *Sanofi Genzyme; *Seattle Genetics; *Shire; Sobi, Inc.; Spectrum Pharmaceuticals, Inc.; St. Baldrick's Foundation; Swedish Orphan Biovitrum, Inc.; *Takeda Oncology; University of Minnesota; University of Pittsburgh; University of Texas-MD Anderson; University of Wisconsin - Madison and Viracor Eurofins. The views expressed in this article do not reflect the official policy or position of the National Institute of Health, the Department of the Navy, the Department of Defense, Health Resources and Services Administration (HRSA) or any other agency of the U.S. Government. ${ }^{*}$ Corporate Members.

\section{References}

1. Goldstone AH, Richards SM, Lazarus HM, et al. In adults with standard-risk acute lymphoblastic leukemia, the greatest benefit is achieved from a matched sibling allogeneic transplantation in first complete remission and an autologous transplantation is less effective than conventional consolidation maintenance chemotherapy in all patients: final results of the International ALL Trial (MRC UKALL XII/ECOG E2993). Blood. 2008;111(4):1827-1833.
2. Aldoss I, Tsai NC, Slovak ML, et al Cytogenetics does not impact outcomes in adult patients with acute lymphoblastic leukemia undergoing allogeneic hematopoietic cell transplantation. Biol Blood Marrow Transplant. 2016;22(7):1212-2017.

3. Shimizu H, Saitoh Y, Okamoto S, et al 
Prognostic impact of cytogenetic abnormalities in adult patients with Philadelphia-chromosome (Ph)-negative acute lymphoblastic leukemia (ALL) who underwent allogeneic stem cell transplant (allo-SCT). Blood. 2015;126(23):2024.

4. Lafage-Pochitaloff M, Baranger L, Hunault $\mathrm{M}$, et al. Impact of cytogenetic abnormalities in adults with $\mathrm{Ph}$-negative B-cell precursor acute lymphoblastic leukemia. Blood. 2017;130(16):1832-1844.

5. Shaffer L, McGowan J, Schmid M. ISCN 2013: An International System for Human Cytogenetic Nomenclature. Basel. S Krager AG, 2012.

6. Moorman AV, Harrison CJ, Buck GA, et al. Karyotype is an independent prognostic factor in adult acute lymphoblastic leukemia (ALL): analysis of cytogenetic data from patients treated on the Medical Research Council (MRC) UKALLXII/Eastern Cooperative Oncology Group (ECOG) 2993 trial. Blood. 2007;109(8):3189-3197.

7. Moorman AV, Chilton L, Wilkinson J, Ensor HM, Bown N, Proctor SJ. A population-based cytogenetic study of adults with acute lymphoblastic leukemia. Blood. 2010;115(2): 206214.

8. Pullarkat V, Slovak ML, Kopecky KJ, Forman SJ, Appelbaum FR. Impact of cytogenetics on the outcome of adult acute lymphoblastic leukemia: results of Southwest Oncology Group 9400 study. Blood. 2008;111(5):25632572.

9. Bassan R, Spinelli O, Oldani E, et al. Improved risk classification for risk-specific therapy based on the molecular study of minimal residual disease (MRD) in adult acute lymphoblastic leukemia (ALL). Blood. 2009;113(18):4153-4162.

10. Zhang X, Zhang MJ. SAS macros for estimation of direct adjusted cumulative incidence curves under proportional subdistribution hazards models. Comput Methods Programs Biomed. 2011;101(1):87-93.

11. Zhang X, Loberiza FR, Klein JP, Zhang MJ. A SAS macro for estimation of direct adjusted survival curves based on a stratified Cox regression model. Comput Methods Programs Biomed. 2007;88(2):95-101.

12. Paulsson K, Johansson B. High hyperdiploid childhood acute lymphoblastic leukemia. Genes Chromosomes Cancer. 2009;48(8): 637-660.
13. Hakeem A, Shiekh AA, Bhat GM, Lone AR Prognostification of ALL by cytogenetics. Indian J Hematol Blood Transfus. 2015;31 (3):322-331.

14. Breems DA, Lowenberg B. Acute myeloid leukemia with monosomal karyotype at the far end of the unfavorable prognostic spectrum. Haematologica. 2011;96(4):491-493.

15. Breems DA, Van Putten WL, De Greef GE, et al. Monosomal karyotype in acute myeloid leukemia: a better indicator of poor prognosis than a complex karyotype. J Clin Oncol. 2008;26(29):4791-4797.

16. Motllo C, Ribera JM, Morgades M, et al. Prognostic significance of complex karyotype and monosomal karyotype in adult patients with acute lymphoblastic leukemia treated with risk-adapted protocols. Cancer. 2014:120(24):3958-3964.

17. Kenderian SS, Al-Kali A, Gangat N, et al. Monosomal karyotype in Philadelphia chromosome-negative acute lymphoblastic leukemia. Blood Cancer J. 2013;3(7):e122.

18. Esteve J, Labopin M, Czerw $T$, et al. Allogeneic hematopoietic cell transplantation (alloHCT) for adult patients with $\mathrm{t}(4 ; 11)(\mathrm{q} 21 ; \mathrm{q} 23)$ KMT2A/AFF1 (MLL/AF4) B-acute lymphoblastic leukemia in first complete remission (CR1): favorable outcome of patients with negative minimal residual disease (MRD) status at transplant. a report from the Acute Leukemia Working Party of the European Society for Blood and Bone Marrow Transplantation (ALWP-EBMT). Blood. 2017;130(Suppl 1):669.

19. Marks DI, Moorman AV, Chilton L, et al. The clinical characteristics, therapy and outcome of 85 adults with acute lymphoblastic leukemia and $\mathrm{t}(4 ; 11)(\mathrm{q} 21 ; \mathrm{q} 23) / \mathrm{MLL}-\mathrm{AFF} 1$ prospectively treated in the UKALLXII/ECOG2993 trial. Haematologica. 2013:98(6):945-952.

20. Moore S, Suttle J, Bain S, Story C, Rice M. Acute lymphoblastic leukemia characterized by $\mathrm{t}(8 ; 14)(\mathrm{q} 11.2 ; \mathrm{q} 32)$. Cancer Genet Cytogenet. 2003;141(1):1-4

21. Messinger $\mathrm{YH}$, Higgins RR, Devidas $M$ Hunger SP, Carroll AJ, Heerema NA. Pediatric acute lymphoblastic leukemia with a $\mathrm{t}(8 ; 14)(\mathrm{q} 11.2 ; \mathrm{q} 32)$ : B-cell disease with a high proportion of Down syndrome: a Children's Oncology Group study. Cancer Genet. 2012;205(9):453-458.
22. Kubo Y, Kakazu N, Tasaka T, et al. Acute lymphoblastic leukemia (ALL) with $\mathrm{t}(8 ; 14)(\mathrm{q} 11.2 ; \mathrm{q} 32)$ in an elderly patient. Leuk Res. 2010;34(3):e82-84.

23. Dyer MJ, Akasaka T, Capasso M, et al Immunoglobulin heavy chain locus chromosomal translocations in B-cell precursor acute lymphoblastic leukemia: rare clinical curios or potent genetic drivers? Blood. 2010;115(8): 1490-1499.

24. Liu W, Hu S, Konopleva M, et al. De novo MYC and BCL2 double-hit B-cell precursor acute lymphoblastic leukemia (BCP-ALL) in pediatric and young adult patients associated with poor prognosis. Pediatr Hematol Oncol. 2015;32(8):535-547.

25. Russell LJ, Enshaei A, Jones L, et al. IGH@ translocations are prevalent in teenagers and young adults with acute lymphoblastic leukemia and are associated with a poor outcome. J Clin Oncol. 2014;32(14):1453-1462.

26. Herold T, Schneider S, Metzeler $\mathrm{KH}$, et al. Adults with Philadelphia chromosome-like acute lymphoblastic leukemia frequently have IGH-CRLF2 and JAK2 mutations, persistence of minimal residual disease and poor prognosis. Haematologica. 2017;102 (1):130138

27. Issa GC, Kantarjian HM, Yin CC, et al Prognostic impact of pretreatment cytogenetics in adult Philadelphia chromosome-negative acute lymphoblastic leukemia in the era of minimal residual disease. Cancer. 2017;123(3):459-467.

28. Iacobucci I, Iraci $N$, Messina $M$, et al. IKAROS deletions dictate a unique gene expression signature in patients with adult $\mathrm{B}$ cell acute lymphoblastic leukemia. PloS one. 2012;7(7):e40934.

29. Mullighan CG, Su X, Zhang J, et al. Deletion of IKZF1 and prognosis in acute lymphoblastic leukemia. N Engl J Med. 2009;360(5):470480.

30. Dupuis A, Gaub MP, Legrain M, et al. Biclonal and biallelic deletions occur in $20 \%$ of B-ALI cases with IKZF1 mutations. Leukemia. 2013;27(2):503-507.

31. Moorman AV, Hagemeijer A, Charrin C, Rieder H, Secker-Walker LM. The translocations, $\quad \mathrm{t}(11 ; 19)(\mathrm{q} 23 ; \mathrm{p} 13.1) \quad$ and $\mathrm{t}(11 ; 19)(\mathrm{q} 23 ; \mathrm{p} 13.3):$ a cytogenetic and clinical profile of 53 patients. European 11q23 Workshop participants. Leukemia. 1998; 12(5):805-810 